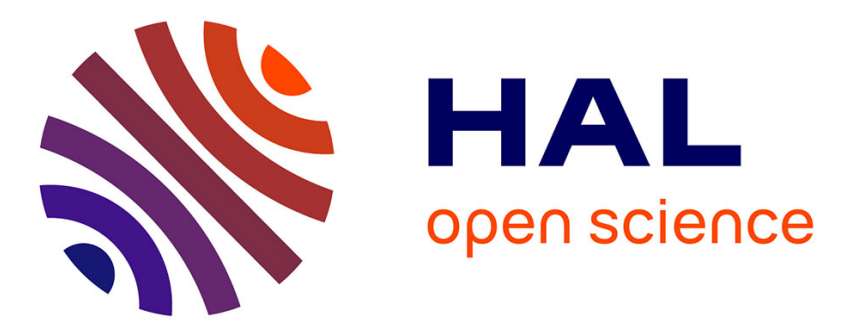

\title{
Malignancies and High Birth Weight in Human: Which Cancers Could Result from Antagonistic Pleiotropy?
}

Fréderic Thomas, Eric Elguero, Jacques Brodeur, Benjamin Roche, Dorothée Missé, Michel Raymond

\section{- To cite this version:}

Fréderic Thomas, Eric Elguero, Jacques Brodeur, Benjamin Roche, Dorothée Missé, et al.. Malignancies and High Birth Weight in Human: Which Cancers Could Result from Antagonistic Pleiotropy?. Journal of Evolutionary Medicine, 2012, 1, pp.1-5. 10.4303/jem/Q120502 . hal-02513097

\section{HAL Id: hal-02513097 \\ https://hal.umontpellier.fr/hal-02513097}

Submitted on 21 Sep 2020

HAL is a multi-disciplinary open access archive for the deposit and dissemination of scientific research documents, whether they are published or not. The documents may come from teaching and research institutions in France or abroad, or from public or private research centers.
L'archive ouverte pluridisciplinaire HAL, est destinée au dépôt et à la diffusion de documents scientifiques de niveau recherche, publiés ou non, émanant des établissements d'enseignement et de recherche français ou étrangers, des laboratoires publics ou privés.

\section{(c)(1)}

Distributed under a Creative Commons Attribution| 4.0 International License 


\title{
Malignancies and High Birth Weight in Human: Which Cancers Could Result from Antagonistic Pleiotropy?
}

\author{
Frédéric Thomas, ${ }^{1,5}$ Eric Elguero, ${ }^{1}$ Jacques Brodeur, ${ }^{2}$ Benjamin Roche, ${ }^{3,5}$ Dorothée Missée, ${ }^{1,5}$ and Michel Raymond ${ }^{4}$ \\ ${ }^{1}$ MIVEGEC, UMR CNRS-IRD 5290, 911 Avenue Agropolis, BP 64501, FR-34394 Montpellier Cedex 5, France \\ ${ }^{2}$ IRBV, Department of Biological Sciences, University of Montreal, 4101 Sherbrooke Street E., Montreal, Quebec, Canada H1X $2 B 2$ \\ ${ }^{3}$ International Center for Mathematical and Computational Modeling of Complex Systems (UMI IRD/UPMC UMMISCO), \\ 32 Avenue Henri Varagnat, 93143 Bondy Cedex, France \\ ${ }^{4}$ Institute of Evolutionary Sciences Montpellier (ISEM), University of Montpellier II, Place Eugene Bataillon, CC065, \\ 34095 Montpellier Cedex 5, France \\ ${ }^{5}$ CREEC, 95 rue de la Galera, 34090 Montpellier, France \\ Address correspondence to Frédéric Thomas, frederic.thomas2@ird.fr
}

Received 28 March 2012; Revised 21 May 2012, Accepted 28 May 2012

\begin{abstract}
Persistence of cancer over evolutionary times is a challenging question for scientists. We explored here the idea that cancer might result from negative tradeoffs of adaptations that improve early survival and/or reproductive fitness. We focused on birth weight since this life history trait has a genetic basis and is also associated with fitness benefits early in life, especially survival. Our analysis includes 107 to 109 countries, 46 types of cancer and various potentially confounding variables. High birth weight was associated with an elevated incidence of ten cancers: kidney cancer, melanoma, multiple myeloma and pancreatic cancer, all four in both men and women, plus prostate and bladder cancers in men. These results, though correlational, suggest that antagonistic pleiotropy should be investigated further as a possible mechanism involved in the causation of cancer in humans.
\end{abstract}

Keywords cancer; antagonistic pleiotropy; birth weight; comparative analysis

\section{Introduction}

Because cancer is an important cause of human mortality (about one-quarter and one-eighth of death in wealthy countries and worldwide, respectively; see [45]), its persistence over time is a challenging question for evolutionary biologists [17]. Recent advances in evolutionary medicine have highlighted that cancer-causing genes (oncogenes) can be maintained in populations through various processes. For instance, as for seemingly maladaptive genes in general (see, e.g., [21,31,44]), natural selection is unlikely to strongly select against oncogenes when their negative effects occur after the reproductive life. In accordance with this hypothesis, there is with most common cancers a well-established relationship between clinical incidence and age $[1,14,15]$. Additionally, antagonistic pleiotropy might be an important component in the evolutionary maintenance of oncogenes (see [7] for a review). This hypothesis stipulates that certain genes have opposite effects on fitness at different ages, such that their effects are beneficial in early life, when natural selection is strong, but harmful at later ages, when selection weakens. A convincing example of such a phenomenon has recently been provided by Fernandez and Bowser [11] in Xiphophorus fishes: melanoma-promoting oncogene alleles are associated with larger body size and aggressivity and confer in early life advantages in male-male competition and female mate choice (see also $[10,12]$ ). The idea that cancer in humans might also result from negative trade-offs of adaptations that improve early survival and/or reproductive fitness is currently considered to be a viable hypothesis $[11,35]$.

Birth weight is among the most promising variables to investigate in this context. This life-history trait is influenced by several non-genetic factors (e.g. food availability), but also has a genetic basis (e.g. [8,22,23,39]). Although its relationship to infant mortality is typically U-shaped as a result of stabilizing selection [16,34], it is also well established that higher birth weights (as long as they remain below extreme values) are associated with fitness benefits early in life, especially survival, under a large range of environmental conditions [38]. For instance, infants with a high birth weight have a lower vulnerability to infections compared with those who have a low birth weight, probably because they have better immune functions $[2,4,5,9,13,20$, $25,41,42,43]$. 
Certain genes could therefore mediate antagonistic pleiotropy, associated with selection for enhanced birth weight due to survival benefits early in life at the expense of later increased risk of cancer [35]. Interestingly, several studies have associated greater birth weight with increased adult human cancer risk, but it remains unclear whether birth weight-cancer associations are either site-specific or similar across sites [24,33]. Current evidence links high birth weight to breast cancer [30,40], prostate cancer [6,29] and colorectal cancer [28]. Here, we tackle this question using a global geographical approach (see, e.g., [36,37]). Variations in birth weight and incidence of several cancers from nation to nation provide an opportunity for a comparative study throughout the world.

\section{Materials and methods}

\subsection{Data}

Worldwide statistics on 46 cancers in women and men (oesophagus; stomach; bladder; brain, nervous system; nasopharynx; lip, oral cavity; larynx; other pharynx; leukaemia; colorectum; liver; gallbladder; pancreas; lung; melanoma of skin; breast; cervix uteri; corpus uteri; ovary; kidney; thyroid; Hodgkin lymphoma; non-Hodgkin lymphoma; multiple myeloma; prostate; testis) were obtained from the International Agency for Research on Cancer (IARC GLOBOCAN project, 2008, http://globocan.iarc.fr/). We did not consider mortality data since this variable is influenced (at least for certain cancers) by the access to therapies - a parameter that strongly varies between countries. Instead, we used incidence data (age-standardized rate) that derive from population-based cancer registries. Although the quality of data varies among countries, this information is still of unique importance as it often remains the only relatively unbiased source of information available on the profile of cancer (IARC, 2008).

International data on mean birth weight and percentage of pre-term birth (i.e., below 37 weeks) were from a dataset available from the World Health Organization (WHO), and already analyzed by Thomas et al. [38] in an evolutionary context. Data on dietary energy consumption, kcal/person/ day, was from the FAO (www.fao.org/economic/ess/ess-fs/ fs-data/ess-fadata/en/). Data on the per capita gross domestic product (GDP) for each country are available at https:// www.cia.gov/library/publications/the-world-factbook/rankorder/2004rank.html.

\subsection{Analyses}

Linear regression was used to study the association between birth weight and log-transformed incidence of several cancers. Because national wealth might influence detection of cancer as well as birth weight, we controlled for national wealth by including the logarithm of per capita GPD in the models. Two other potentially confounding variables were included: average daily caloric intake and mean latitude as a surrogate for environmental factors. The prematurity rate was considered as a potential confounder. Male and female cancers were analyzed separately.

\section{Results}

Data were obtained for 107 to 109 countries, depending on the type of cancer. Some countries reported null incidence rates for some cancers. We assumed these figures were not reliable and excluded them. The cancers significantly associated with a higher birth weight are kidney cancer, melanoma, multiple myeloma and pancreatic cancer, all four in both men and women, plus prostate and bladder cancers in men. Cancer of the lips and oral cavity in women is also significantly associated with birth weight, although the association is in the opposite direction (a higher birth weight is associated with a lower incidence of this type of cancer). All results are summarized in Tables 1 (male) and 2 (female), where odds-ratios are given for an increase in birth weight of one standard deviation. Among confounders, only per capita GDP is consistently positively associated with cancer incidences.

\section{Discussion}

Assuming that cancers in humans might result from negative trade-offs of adaptations that improve early survival (as in Xiphophorus fishes, see Section 1), the objective of this study was to identify those cancers for which we cannot reject this hypothesis. Several interesting results emerge from our study. First, all significant relationships follow the direction predicted by the antagonistic pleiotropy hypothesis, namely higher birth weights are associated with higher cancer incidences, except for one cancer (lips and oral cavity in women). These findings are unlikely to result from a confounding effect of nutritional variables, which could promote both elevated cancer incidence [19] and high birth weight, because we considered both GDP and average daily caloric intake in our analysis. Second, to our knowledge, our study is the first to document an association between birth weight and cancer incidence for bladder cancer, kidney cancer, melanoma, multiple myeloma and pancreatic cancer. Our findings only partially support those from other studies; for instance, we confirmed that prostate cancer and birth weight are positively associated [6,29], but we did not detect significant association with breast and colorectal cancers $[28,30,40]$. Third, the best documented case of cancer maintained by antagonistic pleiotropy concerns a fish melanoma [11], and the most significant association detected here also relates to a melanoma (both in men and women). Clearly, further research is necessary to determine the proximate links between birth weight and different types of tumors. Another interesting research direction would be to explore the links between cancer 
Table 1: Association between birth weight and cancer incidences in males. Odds-ratios and 95\% confidence intervals are given for a birth weight increase of one standard deviation.

\begin{tabular}{|c|c|c|c|}
\hline $\begin{array}{l}\text { Cancer } \\
\text { location } \\
\text { or type }\end{array}$ & $\begin{array}{l}\text { Odds-ratio } \\
\text { (95\% C.I.) }\end{array}$ & $P$-value & $\begin{array}{l}\text { Significance } \\
\text { after Bonferroni } \\
\text { correction }\end{array}$ \\
\hline Bladder & $1.40(1.19-1.64)$ & 0.000082 & $* *$ \\
\hline Brain & $1.08(0.87-1.35)$ & 0.47 & \\
\hline Gall bladder & $1.02(0.81-1.29)$ & 0.87 & \\
\hline $\begin{array}{l}\text { Hodgkin's } \\
\text { lymphoma }\end{array}$ & $1.11(0.94-1.31)$ & 0.23 & \\
\hline Kidney & $1.38(1.17-1.62)$ & 0.00017 & $* *$ \\
\hline Larynx & $0.93(0.79-1.11)$ & 0.42 & \\
\hline Leukaemia & $1.19(1.01-1.39)$ & 0.035 & \\
\hline $\begin{array}{l}\text { Lips_-oral } \\
\text { cavity }\end{array}$ & $0.84(0.71-1.00)$ & 0.059 & \\
\hline Liver & $0.91(0.73-1.13)$ & 0.39 & \\
\hline Lung & $0.98(0.82-1.19)$ & 0.86 & \\
\hline Melanoma & $1.85(1.43-2.40)$ & 0.0000095 & $* * *$ \\
\hline $\begin{array}{l}\text { Multiple } \\
\text { myeloma }\end{array}$ & $1.45(1.21-1.75)$ & 0.00015 & $* *$ \\
\hline Nasopharynx & $0.84(0.64-1.11)$ & 0.22 & \\
\hline $\begin{array}{l}\text { Non-Hodgkin } \\
\text { lymphoma }\end{array}$ & $1.17(1.04-1.32)$ & 0.010 & \\
\hline Oesophagus & $1.15(0.90-1.48)$ & 0.27 & \\
\hline Other pharynx & $0.74(0.59-0.92)$ & 0.0088 & \\
\hline Pancreas & $1.34(1.15-1.55)$ & 0.00025 & $*$ \\
\hline Prostate & $1.65(1.33-2.05)$ & 0.000018 & $* *$ \\
\hline Stomach & $1.11(0.91-1.37)$ & 0.31 & \\
\hline Colorectal & $1.23(1.08-1.40)$ & 0.0025 & \\
\hline Testis & $1.30(1.03-1.65)$ & 0.030 & \\
\hline Thyroid & $1.03(0.86-1.23)$ & 0.75 & \\
\hline
\end{tabular}

incidence and reproductive success, or traits associated with reproductive success such as stature for males [27,32].

Early childhood cancers are sometimes correlated with high birth weight (e.g. acute lymphoblastic leukemia, acute myeloid leukemia diagnosed before two years of age, Wilms' tumor, and neuroblastoma $[3,46])$. Such correlations suggest that causal mechanisms other than post-reproductive costs for early life gains may operate for some cancers. Studies are needed to address why high birth weight is associated with development of such early-onset cancers and whether similar explanations might apply to the late-onset cancers.

We would like to underline some potential limitations of this study. As for all medical geography studies, selecting the appropriate potential confounding variables is critically important, and despite our effort to control for various effects, we cannot exclude the possibility that other
Table 2: Association between birth weight and cancer incidences in females. Odds-ratios and 95\% confidence intervals are given for a birth weight increase of one standard deviation

\begin{tabular}{|c|c|c|c|}
\hline $\begin{array}{l}\text { Cancer } \\
\text { location } \\
\text { or type }\end{array}$ & $\begin{array}{l}\text { Odds-ratio } \\
\text { (95\% C.I.) }\end{array}$ & $P$-value & $\begin{array}{l}\text { Significance } \\
\text { after Bonferroni } \\
\text { correction }\end{array}$ \\
\hline Bladder & $1.25(1.05-1.50)$ & 0.016 & \\
\hline Brain & $1.06(0.88-1.28)$ & 0.53 & \\
\hline Breast & $1.15(1.03-1.27)$ & 0.011 & \\
\hline Corpus uteri & $1.22(1.05-1.41)$ & 0.0091 & \\
\hline Cervix uteri & $0.94(0.80-1.11)$ & 0.49 & \\
\hline Gall bladder & $0.96(0.73-1.25)$ & 0.75 & \\
\hline $\begin{array}{l}\text { Hodgkin's } \\
\text { lymphoma }\end{array}$ & $1.17(1.00-1.38)$ & 0.059 & \\
\hline Kidney & $1.29(1.11-1.49)$ & 0.0013 & $*$ \\
\hline Larynx & $0.77(0.65-0.93)$ & 0.0068 & \\
\hline Leukaemia & $1.05(0.91-1.22)$ & 0.48 & \\
\hline $\begin{array}{l}\text { Lips-oral } \\
\text { cavity }\end{array}$ & $0.79(0.69-0.90)$ & 0.00071 & $* *$ \\
\hline Liver & $0.91(0.73-1.12)$ & 0.36 & \\
\hline Lung & $1.00(0.80-1.24)$ & 0.99 & \\
\hline Melanoma & $2.10(1.57-2.81)$ & 0.0000026 & $* * *$ \\
\hline $\begin{array}{l}\text { Multiple } \\
\text { myeloma }\end{array}$ & $1.45(1.21-1.75)$ & 0.00015 & $* *$ \\
\hline Nasopharynx & $0.94(0.71-1.23)$ & 0.64 & \\
\hline $\begin{array}{l}\text { Non-Hodgkin } \\
\text { lymphoma }\end{array}$ & $1.16(1.00-1.33)$ & 0.047 & \\
\hline Oesophagus & $0.96(0.73-1.24)$ & 0.73 & \\
\hline Other pharynx & $0.75(0.61-0.93)$ & 0.010 & \\
\hline Ovary & $1.05(0.95-1.15)$ & 0.37 & \\
\hline Pancreas & $1.31(1.11-1.53)$ & 0.0014 & $*$ \\
\hline Stomach & $1.06(0.86-1.31)$ & 0.57 & \\
\hline Colorectal & $1.23(1.08-1.40)$ & 0.0023 & \\
\hline Thyroid & $1.08(0.90-1.30)$ & 0.42 & \\
\hline
\end{tabular}

${ }^{*} P$-value $<0.05$ (0.002 with Bonferroni correction).

${ }^{* *} P$-value $<0.01$ ( 0.00041 with Bonferroni correction).

${ }^{* * *} P$-value $<0.001$ (0.000022 with Bonferroni correction).

variables may have influenced with our results. It is possible that other important nutritional aspects are not captured by our variables. Similarly, the different geographic scales considered in literature may be responsible for the differences between some of our findings and previous reported results. Earlier studies have focused at a country scale and, consecutively, can be less influenced by confounding factors like GDP that can scramble this relationship between birth weight and cancer incidence. Our study considers a global scale that allows to study a larger variability in birth weights as well as in cancer incidence rates. As a result, our statistical analysis is expected to be more robust. In addition, we must keep in mind that analyses of data aggregated at the population level may not pertain to individual risk $[18,26]$. Despite these limitations, we believe that these correlational results suggest that antagonistic pleiotropy should continue 
to be investigated as a process maintaining oncogenes in human populations, in particular for the ten cancers identified in our study.

Acknowledgments This work was supported by the French consortium Evolution et Cancer (CNRS).

\section{References}

[1] L. Balducci and W. B. Ershler, Cancer and ageing: a nexus at several levels, Nat Rev Cancer, 5 (2005), 655-662.

[2] G. B. Bukenya, T. Barnes, and N. Nwokolo, Low birthweight and acute childhood diarrhoea: evidence of their association in an urban settlement of Papua New Guinea, Ann Trop Paediatr, 11 (1991), 357-362.

[3] R. W. Caughey and K. B. Michels, Birth weight and childhood leukemia: a meta-analysis and review of the current evidence, Int J Cancer, 124 (2009), 2658-2670.

[4] M. C. Cerqueiro, P. Murtagh, A. Halac, M. Avila, and M. Weissenbacher, Epidemiologic risk factors for children with acute lower respiratory tract infection in Buenos Aires, Argentina: a matched case-control study, Rev Infect Dis, 12 (1990), S1021S1028.

[5] R. K. Chandra, Nutrition and the immune system: an introduction, Am J Clin Nutr, 66 (1997), 460S-463S.

[6] S. Cnattingius, F. Lundberg, S. Sandin, H. Grönberg, and A. Iliadou, Birth characteristics and risk of prostate cancer: the contribution of genetic factors, Cancer Epidemiol Biomarkers Prev, 18 (2009), 2422-2426.

[7] B. J. Crespi and K. Summers, Positive selection in the evolution of cancer, Biol Rev Camb Philos Soc, 81 (2006), 407-424.

[8] I. Emanuel, H. Filakti, E. Alberman, and S. J. Evans, Intergenerational studies of human birthweight from the 1958 birth cohort. 1. Evidence for a multigenerational effect, Br J Obstet Gynaecol, 99 (1992), 67-74.

[9] A. C. Ferguson, Prolonged impairment of cellular immunity in children with intrauterine growth retardation, J Pediatr, 93 (1978), 52-56.

[10] A. A. Fernandez, A cancer-causing gene is positively correlated with male aggression in Xiphophorus cortezi, J Evol Biol, 23 (2010), 386-396.

[11] A. A. Fernandez and P. R. Bowser, Selection for a dominant oncogene and large male size as a risk factor for melanoma in the Xiphophorus animal model, Mol Ecol, 19 (2010), 3114-3123.

[12] A. A. Fernandez and M. R. Morris, Mate choice for more melanin as a mechanism to maintain a functional oncogene, Proc Natl Acad Sci U S A, 105 (2008), 13503-13507.

[13] W. Fonseca, B. R. Kirkwood, C. G. Victora, S. R. Fuchs, J. A. Flores, and C. Misago, Risk factors for childhood pneumonia among the urban poor in Fortaleza, Brazil: a case-control study, Bull World Health Organ, 74 (1996), 199-208.

[14] S. A. Frank, Age-specific acceleration of cancer, Curr Biol, 14 (2004), 242-246.

[15] S. A. Frank, Age-specific incidence of inherited versus sporadic cancers: a test of the multistage theory of carcinogenesis, Proc Natl Acad Sci U S A, 102 (2005), 1071-1075.

[16] D. Futuyma, Evolutionary Biology, Sinauer Associates, Sunderland, MA, 3rd ed., 1998.

[17] M. Greaves, Darwinian medicine: a case for cancer, Nat Rev Cancer, 7 (2007), 213-221.

[18] S. Greenland and H. Morgenstern, Ecological bias, confounding, and effect modification, Int J Epidemiol, 18 (1989), 269-274.

[19] S. D. Hursting, S. M. Smith, L. M. Lashinger, A. E. Harvey, and S. N. Perkins, Calories and carcinogenesis: lessons learned from 30 years of calorie restriction research, Carcinogenesis, 31 (2010), 83-89.
[20] A. Ittiravivongs, K. Songchitratna, S. Ratthapalo, and J. Pattaraarechachai, Effect of low birth weight on severe childhood diarrhea, Southeast Asian J Trop Med Public Health, 22 (1991), 557-562.

[21] T. B. Kirkwood, Understanding the odd science of aging, Cell, 120 (2005), 437-447.

[22] M. A. Klebanoff, B. R. Mednick, C. Schulsinger, N. J. Secher, and P. H. Shiono, Father's effect on infant birth weight, Am J Obstet Gynecol, 178 (1998), 1022-1026.

[23] J. Langhoff-Roos, G. Lindmark, K. H. Gustavson, M. GebreMedhin, and O. Meirik, Relative effect of parental birth weight on infant birth weight at term, Clin Genet, 32 (1987), 240-248.

[24] V. A. McCormack, I. dos Santos Silva, I. Koupil, D. A. Leon, and H. O. Lithell, Birth characteristics and adult cancer incidence: Swedish cohort of over 11,000 men and women, Int J Cancer, 115 (2005), 611-617.

[25] S. E. Moore, T. J. Cole, A. C. Collinson, E. M. Poskitt, I. A. McGregor, and A. M. Prentice, Prenatal or early postnatal events predict infectious deaths in young adulthood in rural Africa, Int J Epidemiol, 28 (1999), 1088-1095.

[26] H. Morgenstern, Uses of ecologic analysis in epidemiologic research, Am J Public Health, 72 (1982), 1336-1344.

[27] D. Nettle, Height and reproductive success in a cohort of british men, Hum Nat, 13 (2002), 473-491.

[28] T. I. Nilsen, P. R. Romundstad, R. Troisi, N. Potischman, and L. J. Vatten, Birth size and colorectal cancer risk: a prospective population based study, Gut, 54 (2005), 1728-1732.

[29] T. I. Nilsen, P. R. Romundstad, R. Troisi, and L. J. Vatten, Birth size and subsequent risk for prostate cancer: a prospective population-based study in Norway, Int J Cancer, 113 (2005), 1002-1004.

[30] S. Oberg, S. Cnattingius, S. Sandin, P. Lichtenstein, and A. Iliadou, Birth weight-breast cancer revisited: is the association confounded by familial factors?, Cancer Epidemiol Biomarkers Prev, 18 (2009), 2447-2452.

[31] L. Partridge and D. Gems, Mechanisms of ageing: public or private?, Nat Rev Genet, 3 (2002), 165-175.

[32] B. Pawlowski, R. I. Dunbar, and A. Lipowicz, Tall men have more reproductive success, Nature, 403 (2000), 156.

[33] J. A. Ross, High birthweight and cancer: evidence and implications, Cancer Epidemiol Biomarkers Prev, 15 (2006), 1-2.

[34] S. Stearns and R. Hoekstra, Evolution: an Introduction, Oxford University Press, New York, 2nd ed., 2005.

[35] K. Summers and B. J. Crespi, Xmrks the spot: life history tradeoffs, sexual selection and the evolutionary ecology of oncogenesis, Mol Ecol, 19 (2010), 3022-3024.

[36] F. Thomas, E. Elguero, J. Brodeur, J. Le Goff, and D. Missé, Herpes simplex virus type 2 and cancer: a medical geography approach, Infect Genet Evol, 11 (2011), 1239-1242.

[37] F. Thomas, K. D. Lafferty, J. Brodeur, E. Elguero, M. GauthierClerc, and D. Missé, Incidence of adult brain cancers is higher in countries where the protozoan parasite Toxoplasma gondii is common, Biol Lett, 8 (2012), 101-103.

[38] F. Thomas, A. T. Teriokhin, E. V. Budilova, S. P. Brown, F. Renaud, and J. F. Guegan, Human birthweight evolution across contrasting environments, J Evol Biol, 17 (2004), 542-553.

[39] B. Towne, S. Guo, A. F. Roche, and R. M. Siervogel, Genetic analysis of patterns of growth in infant recumbent length, Hum Biol, 65 (1993), 977-989.

[40] L. J. Vatten, T. I. Nilsen, S. Tretli, D. Trichopoulos, and P. R. Romundstad, Size at birth and risk of breast cancer: prospective population-based study, Int J Cancer, 114 (2005), 461-464.

[41] C. G. Victora, F. C. Barros, B. R. Kirkwood, and J. P. Vaughan, Pneumonia, diarrhea, and growth in the first $4 y$ of life: a longitudinal study of 5914 urban brazilian children, Am J Clin Nutr, 52 (1990), 391-396. 
[42] C. G. Victora, P. G. Smith, J. P. Vaughan, L. C. Nobre, C. Lombardi, A. M. Teixeira, et al., Influence of birth weight on mortality from infectious diseases: a case-control study, Pediatrics, 81 (1988), 807-811.

[43] C. G. Victora, P. G. Smith, J. P. Vaughan, L. C. Nobre, C. Lombardi, A. M. Teixeira, et al., Infant feeding and deaths due to diarrhea: a case-control study, Am J Epidemiol, 129 (1989), 1032-1041.

[44] G. C. Williams, Pleiotropy, natural selection, and the evolution of senescence, Evolution, 11 (1957), 398-411.

[45] World Health Organization, World Health Statistics 2008, WHO, Geneva, 4th ed., 2008.

[46] M. W. Yeazel, J. A. Ross, J. D. Buckley, W. G. Woods, K. Ruccione, and L. L. Robison, High birth weight and risk of specific childhood cancers: a report from the Children's Cancer Group, J Pediatr, 131 (1997), 671-677. 